\title{
A INTERIORIZAÇÃO DA ASSISTÊNCIA À INFÂNCIA DURANTE A PRIMEIRA REPÚBLICA: DE SÃO PAULO A RIBEIRÃO PRETO
}

Sérgio C. Fonseca*

RESUMO: A interiorização em análise neste texto refere-se a uma região e sua cidade expoente, Ribeirão Preto, que, entre o final do século XIX e o início do XX, se recriou devido à cafeicultura, à ferrovia, ao trabalho assalariado, à imigração e ao aumento demográfico, motivador de sua urbanização. Devido a esses processos, a cidade experimentou diversos problemas sociais, entre os quais o abandono de crianças. Para resolver o abandono de crianças, assim como prover os cuidados médicos e higiênicos com a infância e lidar com a delinquência infanto-juvenil, os modelos institucionais adotados na cidade imitaram ou incorporam elementos das práticas assistenciais vigentes no início da Primeira República, sobretudo daquelas estabelecidas na capital paulista. Assim, o propósito deste artigo é demonstrar que o Asilo Anália Franco, o Instituto de Proteção e Assistência à Infância e o Patronato "Diogo Feijó" são exemplos do processo de interiorização da assistência à infância em Ribeirão Preto.

Palavras-chave: Interiorização. Assistência. Primeira República.

\section{THE INTERNALIZATION OF CHILDHOOD WELFARE}

\section{ALONG THE FIRST REPUBLIC IN BRAZIL: FROM SÃO PAULO TO RIBEIRÃO PRETO}

ABSTRACT: The internalization, in analysis in this text refers to a region and its exponent city, Ribeirão Preto, from late nineteenth to early twentieth century, which was reformed/altered due to coffee farming, the arrival of the railroad, paid labor, immigration and the resultant increase of population, leading to it becoming urbanized.

Due to these processes, the city experienced many social problems, including the abandonment of children. To respond to the abandonment of children, as well as providing medical care, and hygiene, to children and to deal with juvenile delinquency, the institutional models adopted by the city, imitated or incorporated elements of existing care practices utilized at the beginning of the First Republic, especially those established in the state capital, São Paulo. Thus, the purpose of this paper is to demonstrate that the Asilo Anália Franco, the Institute for Protection and Assistance of Children, and the Patronage of "Diogo Feijó" are examples of this process of child care in Ribeirão Preto. Keywords: Internalization. Welfare. First Republic.

* Doutor em Educação Escolar pela Univeridade Estadual Paulista Júlio de Mesquita Filho (UNESP) e Professor Doutor no Departamento de Educação, Informação e Comunicação da Faculdade de Filosofia, Ciências e Letras de Ribeirão Preto (FFCLRP) da Universidade de São Paulo (USP). E-mail: sergiofonseca@ffclrp.usp.br 


\section{A assistência pública à infância}

\section{e a complementaridade das organizações privadas}

No dia 14 de maio de 1922, na inauguração do novo prédio do "Asylo de Orphans Anália Franco de Ribeirão Preto", a Sra. Anita dos Santos, diretora do asilo, avisava que, a partir de então, a cidade podia contar "em seu seio, além das muitas instituições de ensino, também um Asylo para amparar, educar e instruir creanças orphans e pobres" (ASYLO, 1922a, p. 6).

Desde 1917, ano de sua fundação, o "Asilo de Orphans Anália Franco" atuava na cidade, recebendo e cuidando de meninas pobres e órfãs. Datam de 1922 o término da obra e a inauguração da nova sede, ocasião do discurso da diretora, registrado no livro de atas do asilo, aberto nesse momento. Até então, essa era a única instituição na cidade com as características delineadas na época para um orfanato: recebia crianças pequenas, abandonadas ou deixadas pelos pais, na totalidade, pobres; cuidava de sua criação e oferecia alguma instrução escolar e para o trabalho. Quanto aos meios empregados para se sustentar e praticar o que se propunha, contava com auxílios e subvenções públicas, sempre parciais e insuficientes, e com a contribuição em serviços, em dinheiro e gêneros oferecidos pela população. Completavam esses meios de manutenção da instituição as relações estabelecidas entre seus mantenedores e os representantes das elites econômicas e políticas locais, em geral ocupantes de funções públicas, fato atestado pela presença do prefeito da cidade, João Rodrigues Guião, nessa cerimônia de inauguração. Pouco tempo depois, esse mesmo prefeito reconheceu, no relatório sobre sua gestão, entre 1920 e 1923, que "a iniciativa privada tem feito muito em prol do movimento social, principalmente no que diz respeito à assistência às classes pobres", em especial o "asilo de orphans Anália Franco, a Sociedade Amiga dos Pobres, a Sociedade de Assistência à Infância, a Sociedade S. Vicente de Paula e o Asilo de Mendicidade" (CÂMARA MUNICIPAL, 1924, p. 8).

Antes, em 1909, Candido Mota (1909, p. 35) elogiava o serviço prestado por estabelecimentos privados à infância pobre e abandonada na cidade de São Paulo, listando entre os mais ativos o "Lyceo do Sagrado Coração de Jesus, fundado e dirigido pelos revdms. padres Salesianos", que, para ele, era "uma instituição digna de proteção". Mota (1909, p. 35) 
assinalava, ainda, o apoio estatal a outro estabelecimento colocado na mesma ordem de importância, pois "assim o tem entendido os poderes públicos", que não "tem regateado auxílios e subvenções pecuniárias" destinados ao "Instituto 'D. Anna Rosa', fundado e mantido às expensas da ilustre família Sousa Queiroz, e que tão bons auxílios tem prestado á orphams e meninos pobres" na capital paulista.

Menos de vinte anos após o elogio de Mota, no relatório de sua administração interina do Estado, ao final de 1927 (ALVES, 1986), Antonio Dino da Costa Bueno assinalava os auxílios prestados por organizações privadas à assistência aos menores na capital paulista, fazendo referência às medidas como a “installação do 'Abrigo Provisório' de menores, o augmento do numero de comissários, mediante contracto" somadas ao "auxilio prestado por diversos asylos particulares - entre os quaes se destacam o do 'Bom Pastor', o da 'Divina Providencia' e o 'Anália Franco', que receberam diversas meninas que lhes foram encaminhadas de accôrdo com a lei, para a respectiva internação", cuja combinação com as ações estatais "contribuiu para que o magno problema da protecção e assistência aos menores tivesse parcial solução" (MENSAGEM, 1927, p. 31).

O ponto comum nos discursos de Candido Mota, do presidente interino do Estado, Antonio Dino, de Anita dos Santos, diretora do asilo ribeirão-pretano, e do prefeito Rodrigues Guião é o reconhecimento da complementaridade do serviço de organizações privadas à assistência pública à infância pobre. A "parcial solução" do "magno problema da proteção e assistência aos menores" é exatamente aquela das organizações privadas, à frente em número e presença na assistência à infância quando comparadas com as ações estatais na cidade de São Paulo (Quadro 1). Desde o século XIX, o número, o tipo e a motivação confirmam o amparo à infância pobre e abandonada como realização quase sempre produzida por pessoas e organizações particulares, por sua vez, inspiradas por ideários humanitário-cristãos ou, quando aparentemente despidos de impregnação religiosa, assumidamente humanitário-filantrópicos, conforme o quadro a seguir: 


\section{QUADRO 1}

Estabelecimentos assistenciais para a infância ativos na cidade de São Paulo entre 1825 e 1897

\begin{tabular}{c|c|c|c} 
Período & Estabelecimento & Ano de fundação & Natureza \\
\hline 1825 & Roda e Casa de Expostos da Santa Casa de Misericórdia & $1824 / 1825$ & Particular \\
$\mathbf{a}$ & Seminário de Educandos de Santana & 1825 (extinto em 1868) & Público \\
1873 & Seminário de Educandas da Glória & 1825 & Público \\
& Instituto de Educandos Artífices & 1869 (extinto em 1880) & Público \\
& Liceu de Artes e Ofícios & 1873 & Particular \\
1892 & Instituto D. Ana Rosa & 1874 & Particular \\
a & Asilo Nossa Senhora Auxiliadora do Ipiranga & 1885 & Particular \\
1897 & Liceu Sagrado Coração de Jesus & 1885 & Particular \\
& Orfanato de Santana & 1892 & Particular \\
& Colégio D. Carolina Tamandaré & 1892 & Particular \\
& Abrigo Santa Maria & 1892 & Particular \\
& Casa Pia São Vicente de Paulo das Damas de Caridade & 1894 & Particular \\
& Orfanato Cristóvão Colombo & 1895 & Particular \\
& Asilo de Órfãos Nossa Senhora Auxiliadora do Ipiranga & 1896 & Particular \\
& Casa da Divina Providência & 1896 & Particular \\
& Asilo de Expostos da Santa Casa de Misericórdia & 1896 & Particular \\
& Casa da Divina Providência da Mooca & 1897 & Particular \\
& Asilo Bom Pastor & 1897 & Particular
\end{tabular}

FONTE: Elaborado pelo autor.

Do começo do século XIX, precisamente a partir de 1825, até meados da década de $1930^{1}$, um dos resultados da ação privada na assistência pública às crianças pobres ou abandonadas na capital paulista é o conjunto de estabelecimentos fundados nesse tempo. Embora asilos, orfanatos, casas de expostos, seminários, liceus e institutos componham tipos peculiares de organizações, dotados de diferenças entre si e de complexidade própria, num exame sumário e geral, podem ser agrupados como integrantes de um sistema majoritariamente privado de criação e tutela de crianças pobres ou abandonadas.

$\mathrm{Na}$ cidade de São Paulo, foi de segmentos externos ao poder público que costumaram partir as iniciativas concretizadas em diferentes tipos de atendimento prestado à infância pobre. No período de 1825 até 1897, a ação de segmentos particulares foi ainda mais numerosa, conforme o Quadro 1, de sorte que os estabelecimentos criados entre 1892 e 1897 são duradouros e permaneceram ativos durante a Primeira República, a ponto de constarem entre aqueles citados por Mota (1909) e por Antonio Dino (MENSAGEM, 1927) como auxiliares ao poder público.

Quanto a Ribeirão Preto, a assistência a alguma forma de necessidade social passou a ser conhecida na cidade, no final do século XIX, 
em razão da Santa Casa de Misericórdia e das associações de socorros mútuos fundadas por imigrantes. Sob o nome de Sociedade Beneficente, a Santa Casa de Misericórdia de Ribeirão Preto, desde 1896, prestava assistência aos doentes na cidade. A fim de realizar esse propósito, a Santa Casa contou com a conjugação de esforços entre religiosos e membros da sociedade local para, ainda que precariamente, se viabilizar como prestadora de assistência a enfermos pobres na cidade.

Será no século XX, durante sua primeira década, que outras sociedades beneficentes e caritativas iniciarão suas atividades em Ribeirão Preto, a exemplo da Sociedade Amiga dos Pobres, criada nessa mesma época. Entre os seus propósitos, sendo o primeiro fundar e manter um abrigo para mendigos, consta uma escola para crianças pobres, obra mantida durante anos por essa sociedade, segundo o memorialista local Prisco da Cruz Prates (1956). A assistência à infância com as características instituídas pelos estabelecimentos paulistanos existentes desde fins do século XIX encontrará seus representantes em Ribeirão Preto na segunda década do século XX. Em 1917, entraram em atividade na cidade o Instituto de Proteção e Assistência à Infância, cujo principal fundador foi o médico Antonio Gouvêa, e o "Asylo de Orphans Anália Franco de Ribeirão Preto". Na década seguinte, alguns textos de jornais locais, como A Cidade, e o relatório da Câmara Municipal e da Prefeitura (CÂMARA MUNICIPAL, 1929) noticiavam a existência, no município, desde 1922, do Patronato Agrícola Diogo Feijó, uma espécie de colônia agrícola para menores criada pelo governo federal e inscrita na estrutura do Ministério da Agricultura (BRASIL, 1918).

Em Ribeirão Preto, portanto, entre 1895 e 1922, três ordens de ações assistenciais atuaram sobre a infância pobre e abandonada, à semelhança das tendências ratificadas na cidade de São Paulo na mesma época. O recolhimento e os cuidados médicos e higiênicos, junto da caridade prestada aos enfermos, contavam com o trabalho da Santa Casa de Misericórdia, desde 1896. Quanto à assistência institucional, o "Asilo de Orphans Anália Franco", ao iniciar suas atividades, em 1917, fez as vezes de instituição capaz de receber e criar meninas órfãs ou, em certas situações excepcionais, entregues pelos pais, nos moldes estabelecidos na época para um orfanato. Por sua vez, o Instituto de Proteção e Assistência à Infância "Dr. Antonio Gouveia" cumpriu o papel de prestador de cuidados médicos e higiênicos às mães e às crianças pobres, reproduzindo 
características dos institutos de proteção espalhados pelo país e inspirados no modelo do Instituto de Proteção e Assistência à Infância (IPAI), do médico fluminense Carlos Arthur Moncorvo Filho. Até mesmo a delinquência infanto-juvenil chegou a ser objeto da ação institucional no tempo em que esteve ativo na cidade o Patronato Agrícola "Diogo Feijó".

Esse conjunto de agentes e instituições atuantes em Ribeirão Preto, quando comparado à história da assistência à infância na cidade de São Paulo, evidencia que as formas de cuidar do abandono e da pobreza de crianças e da menoridade, consagradas no decorrer da Primeira República, tiveram uma ocorrência inicial na capital paulista e a seguida repercussão no interior. Esse movimento de produção de meios de assistir crianças pobres em São Paulo e as semelhanças encontradas em Ribeirão Preto, devido à interiorização de ideias e práticas, pode ser estudado conforme quatro tendências perceptíveis na história da assistência à infância nessa época:

a) Entre o final do século XIX e o começo do XX acontecem três ordens de mudanças verificáveis: na presença, na vida urbana, de crianças nas ruas como fato cotidiano, fossem abandonadas, pobres ou menores; nas formas de entender e cuidar de órfãos e abandonados; na produção das noções de abandono material e moral; e na farta elaboração de legislação sobre infância, tanto federal quanto nos estados;

b) A história da atenção à infância pobre na cidade de São Paulo consagrou as sociedades particulares, os beneméritos, os filantropos, as associações confessionais e outros congêneres como idealizadores, promotores e mantenedores da assistência pública à infância pobre. Essa variedade de organizações e sujeitos, por sua vez, contribuiu para edificar, durante a passagem do século XIX para o XX, as bases do sistema privado de assistência à infância pobre, cujo produto é um conjunto de estabelecimentos fechados, a exemplo de seminários, recolhimentos, asilos e orfanatos;

c) Apesar da existência de alguns seminários e liceus públicos durante o século XIX em São Paulo, as ações de recolhimento, criação e ensino de ofícios em geral foram produzidas por particulares. O poder público estadual, assim como nas instâncias municipais, agiu como subvencionador, a ponto de os governos do Estado, da capital e de Ribeirão Preto naturalizarem a ação privada como compensadora da evasão pública da necessidade de cuidar e assistir a infância pobre; 
d) São Paulo e Ribeirão Preto, no que concerne à interiorização aqui estudada, são, respectivamente, a partida e o extremo do processo. No caso da interiorização da assistência, os modelos e práticas encontrados em Ribeirão Preto durante a Primeira República, embora tenham fortes particularidades, coincidem e, ao mesmo tempo, reproduzem as formas de assistência existentes em São Paulo.

\section{A interiorização paulista em direção a velhos e novos "oestes"}

Pierre Monbeig (1984, p. 23) sintetizou o processo de interiorização paulista sob a forma de marcha das frentes pioneiras de povoamento que foram antecedidas pelo desmatamento, pela territorialização da agricultura e pelas cidades resultantes, desenvolvidas ou criadas na "retaguarda", de maneira que era "preciso ir mais longe, para atingir a frente do povoamento", em meados do século XX. Nessa lógica da marcha em direção ao interior, a cafeicultura, a ferrovia e a imigração fizeram uma região se recriar pela acumulação do capital, pelo trabalho assalariado e pelo crescimento demográfico, o que produziu sua peculiar urbanização. A imigração influenciou ativamente o crescimento populacional e, por que não considerar, a territorialização de contingentes humanos estranhos à zona mogiana do entorno de Ribeirão Preto. Desde 1870, sucessivos contingentes de imigrantes passaram por São Paulo e depois foram levados aos núcleos urbanos do complexo cafeeiro e aí se estabeleceram, conforme o sentido do movimento de interiorização da exploração econômica das terras de cultivo de café. O fluxo da imigração partia de São Paulo para o interior, percorrendo o caminho da ferrovia Mogiana, distribuindo pessoas por pequenas vilas e cidades e, depois, nas fazendas, em suas colônias, fazendo aumentar sua população (MONBEIG, 1984; BACELLAR, 1999).

Ribeirão Preto é exemplo nesse sentido, uma vez que, em 1902 e 1912, quando fez a contagem de sua população, o município tinha, no primeiro censo, na "cidade e nos subúrbios", 13.236 habitantes (CÂMARA MUNICIPAL, 1903, p. 15), passando a 58.220, no segundo recenseamento, em 1912 (CÂMARA MUNICIPAL, 1920, p. 68). Entre esses números, na contagem de 1912, grande parte da população estava nas áreas rurais, essencialmente em colônias de fazendas de café, na con- 
dição de trabalhadores assalariados, contando a cidade com 18.732 habitantes na área urbana e 39.488, na zona rural, sendo 27.000 imigrantes, na quase totalidade italianos (CÂMARA MUNICIPAL, 1920).

Se a cidade foi capaz de contar sua população, ainda que o serviço tenha sido contratado pelas duas instâncias do poder público municipal, Câmara e Prefeitura (CÂMARA MUNICIPAL, 1920), isso demonstra duas formas progressivas de institucionalização em processo no interior, durante o tempo de transição de século entre o XIX e o XX: a primeira é a extensão a Ribeirão Preto de instituições oficiais de representação do Estado, a começar pelo judiciário, pelo policiamento, pelos grupos escolares estaduais; e a segunda é a organização e o funcionamento do legislativo e do executivo da localidade. De acordo com indicações de Lages (1996) e Bacellar (2002), Ribeirão Preto foi fundada em 1854, sendo elevada à condição de vila em 1871 e, em 1892, tornou-se sede da comarca, separando-se de São Simão. Em 1874, o município, já reconhecido assim desde 1871, estabeleceu sua primeira Câmara Municipal, até então e durante a Primeira República respondendo pelo governo da cidade. Nesse ritmo, até 1912, a cidade possuía cadeia, Câmara, Prefeitura e Fórum instalados e atuantes, bem como delegado e subdelegados, Comissão Sanitária, coletoria de impostos e dois ginásios estaduais (CÂMARA MUNICIPAL, 1920).

O fato de Ribeirão Preto entrar o século XX dotada de entes representativos do poder público, sobretudo daqueles encarregados do governo local, é prova do enraizamento de determinados elementos da interiorização, no caso, o estabelecimento de meios de aplicação da justiça, de arrecadação de tributos, de instrução, de controle sanitário e de policiamento. Na lógica da ocupação econômica e da resultante retaguarda aberta, assim entendida por Monbeig (1984), onde cresceram ou nasceram cidades, viabilizadas, entre outras causas, pelo assentamento de populações, pode-se acrescentar que esse processo de interiorização se fez acompanhar pelo estabelecimento da estrutura administrativa e burocrática, viabilizando, assim, os meios de ação institucional sobre a vida social na urbanidade e nos núcleos rurais de habitação e trabalho.

Apesar do estabelecimento de entes administrativos estatais na cidade, dotados de meios de ação, sua eficiência era discutível, uma vez que as funções de policiar, de aplicar a lei, de arrecadar tributos, assim como a incumbência local de gerir a cidade, de legislar e de fiscalizar os cuidados 
sanitários estavam limitadas quanto ao seu alcance. Pesa, para tanto, o fato de os orçamentos públicos municipais não contarem com arrecadação suficiente ou deixarem de destinar recursos, limitando as ações públicas às obras de melhoramento da cidade, manutenção de sua infraestrutura e fiscalização sanitária, restando estreita margem para os parcos serviços oferecidos à população, em geral apoiados na subvenção a organizações privadas prestadoras de assistência aos pobres, por exemplo².

Desde 1896, com a fundação da Sociedade Beneficente Santa Casa de Misericórdia, depois com a Sociedade Amiga dos Pobres, de 1905, com a Sociedade São Vicente de Paulo e com as associações de socorros mútuos das comunidades imigrantes (sendo as primeiras fundadas por italianos, em 1895), entre os exemplos de organizações ativas na cidade, a sociedade ribeirão-pretana acostumou-se a recorrer a meios particulares de ação pública para cuidar dos doentes, assistir os pobres e oferecer educação escolar primária às crianças. A presença dessas organizações e a forma como se modelavam e atuavam, por sua vez, indicam outro aspecto da interiorização: a elaboração de estratégias de ação pública em Ribeirão Preto referenciadas em experiências, ideias e instituições produzidas em outros tempos e lugares. E, uma vez que entraram em atividade, nos relatórios e orçamentos apresentados pelas administrações municipais, entre 1903 e 1930, a Santa Casa, a Sociedade Amiga dos Pobres e a Sociedade São Vicente de Paulo constaram seguidamente como destinatárias de subvenções da municipalidade.

O processo de interiorização, portanto, é composto internamente por interiorizações, como as da população, da cafeicultura, dos profissionais liberais, dos empreendedores, das relações econômicas com o exterior, da urbanização, das representações do poder público e, também, da caridade cristã, da filantropia e da prática dos socorros mútuos, por sua vez representadas pelos agentes e pelas organizações que estabeleceram meios para resolver questões como a assistência aos pobres. Nesse sentido, a igreja católica é uma agente da interiorização em Ribeirão Preto. Até que a Diocese fosse criada na cidade, em 1908, e instalada, em 1910, muito antes, desde 1856 (LAURIANO, 1973), vários religiosos foram convocados de outras paróquias, dioceses e ordens, com o fim de cuidar da assistência espiritual e da religiosidade dos fiéis e, questão igualmente importante, edificar materialmente nas povoações a Igreja na região. Quando os primeiros padres foram nomeados vigários, por volta de 1870, 
não só a vila e seus moradores seriam atendidos, como também "sua missão pastoral" seria estendida à "população rural que vivia em região bastante ampla e difícil, pois abrangia áreas que futuramente seriam ocupadas pelas paróquias de Sertãozinho, Pontal, Guatapará, Santa Cruz das Posses, Cravinhos, Serrana e Serra Azul" (LAURIANO, 1973, p. 25).

Os religiosos, nacionais ou estrangeiros, geralmente faziam sua formação sacerdotal em seminários de Minas Gerais, na cidade de São Paulo ou nas suas pátrias de origem, e realizavam sua "missão pastoral" na cidade e na região de Ribeirão Preto portando convicções que orientavam suas relações com os fiéis e com as obras que realizavam. Os religiosos que atuaram em Ribeirão Preto desde 1870 (LAURIANO, 1973) pertenciam já a uma geração de sacerdotes cuja formação aconteceu sob a influência da romanização da Igreja, durante o pontificado de Pio IX, de sorte que uma das tendências desse processo é a reiteração da autoridade religiosa centrada nos padres e, no caso particular de uma região ainda em processo de crescimento populacional, como Ribeirão Preto, o empenho em cuidar da fé do povo antes que maçons, espíritas e protestantes o fizessem (LAURIANO, 1973).

Por extensão, como parte desse processo de difusão das convicções cristãs-católicas, as obras de caridade passaram a receber o empenho dos religiosos e a convocação aos fiéis para sua adesão na futura Diocese de Ribeirão Preto, realização que se concretizaria em 1908 (LAURIANO, 1973). De início, as esmolas, o serviço religioso dedicado aos enfermos e, a seguir, as obras caritativo/assistenciais estabelecidas, como a Santa Casa de Misericórdia, desde 1896, e o Asilo de Mendicidade "Padre Euclides", em 1919, ao lado das sociedades leigas, como a Conferência de São Vicente de Paulo (e seus membros, os vicentinos), fizeram da Igreja um agente interiorizador das estratégias de ação social em uso nesse tempo.

O contraponto à ação social de fundo religioso fica por conta dos espíritas, que, assim como os religiosos e leigos católicos, são também agentes da interiorização da assistência aos necessitados, em especial das crianças, trazendo para a cidade modelos aplicados de antemão em outros lugares. Para tanto, a história da criação do "Asylo de Orphans Anália Franco" coloca maçons e espíritas como protagonistas do processo meio autóctone e meio modelado por referências externas da produção na cidade de instituições e meios de ação sobre a pobreza e o abandono de crianças. 


\section{A assistência à infância desde o século XIX, em São Paulo}

Em comum, certos memorialistas e estudiosos da história da cidade de São Paulo noticiam a existência de organizações caritativas e assistenciais destinadas à infância pobre na capital paulista desde o início do século XIX. Diferentes textos, de artigos na Revista do Arquivo Municipal, a exemplo de Lowrie (1936), Franco (1944) e Ferreira (1940), de memórias históricas como as de Primitivo Moacyr ou Ernani Silva Bruno (1984), ao dicionário organizado por Amaral (2006), destacam as irmandades, a caridade, a benemerência e o espírito filantrópico de particulares como responsáveis por criar e manter esses estabelecimentos, respondendo quase exclusivamente pela assistência pública à infância paulistana desde o século XIX. No mesmo campo assistencial e na mesma época, o poder público monárquico e sua representação na província ofereceram menor contribuição para a instrução e a tutela de meninos e meninas pobres e abandonados, participando pontualmente, portanto, de um sistema de cuidados públicos cujas iniciativas em geral costumaram partir de organizações particulares.

Entre os estabelecimentos existentes até próximo ao fim do Império, Ferreira (1940), Moacyr (1942) e Amaral (2006) mencionam o Seminário de Educandas da Glória, fundado em 1825, o Seminário de Educandos de Santana, de 1825, e o Instituto de Educandos Artífices, de 1869, como obra dos governos provincial e imperial, respectivamente. O primeiro deles, o Seminário da Glória, foi concebido para receber e cuidar da educação de meninas "órfãs, filhas de militares que, tendo servido à Pátria, morressem indigentes", conforme estabelecia o aviso "expedido pelo Governo Imperial, de 8-1-1825” (AMARAL, 2006, p. 582). Outro congênere seu, o Seminário de Santana, foi idealizado para fins semelhantes, destinado “à educação de meninos órfãos e pobres, especialmente filhos de militares que haviam servido à pátria e morreram indigentes" (AMARAL, 2006, p. 582).

O terceiro estabelecimento, o Instituto de Educandos Artífices, tinha origens parecidas a esses seus similares, "criado pela Lei $n^{\circ} 26$, de 57-1869, com caráter militar, anexo ao Corpo Policial e funcionando em quartel, teve seu regulamento baixado pelo presidente da Província, João Teodoro Xavier, em 3-1-1874” (AMARAL, 2006, p. 343). Esse estabelecimento não sobreviveu até o fim do Império em razão da inconstância 
dos recursos financeiros recebidos do governo provincial e da dificuldade de existir sob o fim de criar e educar órfãos pobres. Por isso, o Seminário de Santana foi extinto em 1868, como atesta Amaral (2006), tendo seu lugar preenchido pelo Instituto de Educandos Artífices, cuja vida institucional não foi longa, porquanto foi extinto em 1880 (AMARAL, 2006). Dos três estabelecimentos criados pelo poder público, apenas o Seminário da Glória seguiu em atividade, atravessando o século XIX para o XX.

Sob propósitos semelhantes, entre 1873 e 1896, foram criados, pela iniciativa de associações particulares, o Liceu de Artes e Ofícios, o Instituto D. Ana Rosa, o Liceu Sagrado Coração de Jesus e o Asilo de Expostos da Santa Casa de Misericórdia de São Paulo (Quadro 1). Em comum, todos foram concebidos pela iniciativa de sociedades civis ou caritativas, quase sempre inspirados por princípios humanitário-religiosos, exceção feita ao primeiro liceu citado, bem como representaram certo tipo de ação assistencial pública organizada por particulares. Uma dessas associações nasceu como Sociedade Propagadora da Instrução Popular, em 1873, para se tornar, em 1882, o Liceu de Artes e Ofícios, cujo fim, desde sua origem, era oferecer escolarização elementar e profissional a meninos pobres. À exceção dos congêneres aqui citados, o Liceu alcançou o século XX ativo, estando, no início da República, "em fase de grande atividade e desenvolvimento, com uma matrícula de 738 alunos", dados estes reunidos por Ferreira (1940, p. 61), continuando suas atividades em tempos republicanos com "583 alunos, sendo do curso primário 320 e do curso secundário 263", conforme os matriculados entre os anos de 1893 e 1894 (MOACYR, 1942, p. 317).

Há registro, ainda, do Colégio D. Carolina Tamandaré, como informa Franco (1944), criado na última década do século XIX, durante a quarta administração estadual paulista na República ${ }^{3}$. A fundação desse colégio resultou da iniciativa de um dos membros do círculo da família Souza Queirós, Manoel Batista da Cruz Tamandaré, que, em homenagem à esposa, D. Carolina de Souza Queirós Tamandaré, e aos filhos, falecidos, recolheu fundos para tanto e contou com o reconhecimento do governo estadual, que atestou sua utilidade, além de destinar subvenções públicas a esse estabelecimento. Assim como os similares da época, o Colégio D. Carolina Tamandaré, conforme definido em seu estatuto (no Decreto n. 91), tinha como finalidade precípua "acommodar, segundo as regras de hygiene, sessenta meninas desvalidas" para difundir "a educação intellec- 
tual, moral e religiosa e ensinar tudo quanto deve saber uma mulher para ganhar honesta e independentemente sua vida e tornar-se uma boa mãe de família" (SÃO PAULO, 1892, p. 1).

Comparando os exemplos provenientes do século XIX, é certo que a assistência privada oferecida ao público respondeu com maior número de estabelecimentos e iniciativas às demandas do amparo à doença, à pobreza, à instrução de meninos e meninas pobres e às crianças órfãs, quando comparada às ações estatais nessa mesma época. As amasde-leite, por exemplo, pagas para alimentar e cuidar de crianças pequenas entregues à roda da Santa de Casa de Misericórdia de São Paulo, fizeram parte de um sistema de criação de órfãos concebido quase totalmente por particulares; algo nomeado por Marcílio (1998, p. 136) como "sistema informal ou privado de criação dos expostos". Quanto à instrução de meninos e meninas pobres, desde a primeira gestão do Estado em tempos republicanos ${ }^{4}$, o orçamento estadual consignou recursos ao "Liceu Coração de Jesus, como auxílio à educação de meninos pobres, conforme contrato", num total de 10:000\$000, e "ao Liceu de Artes e Ofícios, da Propagadora da Instrução Popular, para a educação de meninos pobres" a quantia de 12:000\$000 (FRANCO, 1944, p. 8). Portanto, até fins do século XIX, em São Paulo, a assistência inspirada pelas motivações humanitárias e/ou religiosas, associada aos poderes públicos ou suprindo sua ausência e em resposta à pobreza e ao abandono de crianças, era a forma geral de amparo com que contavam as pessoas, em caso de doença, e a sociedade, em razão dos filhos sem pais ou família ${ }^{5}$.

As raízes desse tipo de ação assistencial foram lançadas desde o século XIX e se firmaram à medida que os estabelecimentos continuaram suas atividades, alcançando o século seguinte, uma vez que passou ao XX a convivência entre a prestação particular de cuidados públicos e a instável ação estatal, no mais das vezes legitimando e subvencionando as organizações assistenciais privadas 6 . Trata-se, portanto, de um grande modelo baseado no recolhimento e na tutela, no caso dos órfãos ou abandonados, ou na instrução para o trabalho, quando se tratava das crianças pobres, cuja característica geral é a assistência institucionalizada. Nesse rol de estabelecimentos mencionados (Quadro 1) constam seminários, institutos e liceus fundados ainda no Império, na então Província de São Paulo, especialmente as instituições ligadas a ordens religiosas, às associações cristãs e católicas, ou aquelas de iniciativa de organizações como a Sociedade 
Propagadora da Instrução Popular, responsável pelo Liceu de Artes e Ofícios (MOACYR, 1942). Tal assistência institucionalizada, por sua vez, consagrou determinados agentes e papéis, sendo beneméritos, associações civis ou ligadas a confissões religiosas, ordens religiosas, membros das elites, intelectuais e ilustrados os propositores de ações institucionalizadas. E, acessoriamente, o poder público mantém instituições próprias, em geral atuando como contratante e subvencionador, o que reiterou igualmente a ação concretizada em modelos institucionais com ênfase no recolhimento, na disciplina, no encaminhamento social e no ensino de ofícios subalternos.

Nota-se, então, que, até a última década do século XIX, a cidade de São Paulo possuía estabelecimentos existentes a tempo suficiente para instituir certas formas de lidar com o problema da infância desvalida que continuaram como referência durante o ciclo de mudanças vivido pela cidade no século seguinte. Ao passo que a assistência privada oferecida ao público seguia ativa, a cidade de São Paulo mudava em vários sentidos, recebendo progressivas somas de imigrantes, experimentando mudanças na relação entre o capital e o trabalho, a exemplo da formação do proletariado urbano, conhecendo a marginalização dos pobres, a delinquência infanto-juvenil, enfim, uma série de processos que alteraram sensivelmente a vida social na capital do Estado em tempos republicanos (CAMPOS, 2004). Nesse sentido, um fato em especial assinala a mudança da cidade sob o ponto de vista humano e social, no caso, o crescimento demográfico, uma vez que sua população passou, num intervalo de tempo entre 1890 a 1900, de 64.934 a 239.820 habitantes $^{7}$, progressão de crescimento que não cessou até 1940, quando o número de um milhão de habitantes foi alcançado (MEMÓRIA, 2001).

Enquanto a cidade crescia em número de habitantes, as possibilidades de ocupação dos bairros, de alimentação, de moradia, enfim, de estabelecimento pelos novos moradores que chegavam à cidade, na entrada do século XX, e assim foi pelas décadas seguintes, encontraram na especulação imobiliária urbana, na pressão do custo de vida e na vigilância policial associada ao urbanismo higienista forças capazes de mover o proletariado urbano e toda sorte de pobres a ocuparem as regiões periféricas em relação ao centro (PETRONE, 2001; REIS, 2004). Para essa cidade em crescimento, convivendo com a novidade dos bairros operários e industriais, por exemplo, aquilo que responderia por serviços públicos 
capazes de atender às necessidades da saúde dessa população, da educação dos seus filhos, de regular as relações entre capital e trabalho, enfim, de minimizar os efeitos colaterais do aumento demográfico era desproporcional em relação ao contingente de necessitados e perante certo conjunto de demandas (CAMPOS, 2004).

É certo que as ações sanitárias e médicas do poder público paulista aconteceram desde a primeira década republicana, no século XIX, e foram ainda mais expressivas a partir de 1900 e nos decênios seguintes, quando foram criados hospitais de isolamento, a Faculdade de Medicina, o Instituto de Higiene, institutos para a produção de vacinas, missões sanitárias no interior, enfim, um conjunto de organizações estatais atuantes na saúde pública (VASCONCELLOS, 1995). Também a instrução, tanto na capital quanto no interior, conheceu o célebre período dos ginásios do estado e da expansão das escolas públicas primárias.

Em comparação com a saúde pública e a instrução, os cuidados com a infância pobre, com as condições da sua criação e mesmo do estabelecimento de estratégias para responder ao abandono e à marginalização ainda dependiam muito das vigentes práticas assistenciais humanitário-filantrópicas, cristãs e caritativas, que, no século XX, continuaram convocadas para remediar as necessidades dos novos pobres e desafortunados da cidade. Desse modo, é possível considerar que a produção de práticas assistenciais na cidade de São Paulo recebeu influência de dois processos, sendo um deles a aceleração do crescimento populacional, acentuado pela imigração, produzindo, por sua vez, a ocupação de áreas possíveis para a moradia, problemas estes conjugados à relação entre exploração do trabalho e formação de contingentes de semi-incluídos, precários ou não incluídos no trabalho, enquanto o segundo processo resultou das ideias, das percepções, dos agentes e dos modos escolhidos e instituídos de assistir à infância desvalida e aos pobres.

\section{A assistência institucionalizada à infância em Ribeirão Preto}

O discurso de Anita dos Santos, citado no início deste texto, naquele dia de inauguração, teve a qualidade de sintetizar determinados elementos inerentes ao modo de manter, ao relacionamento e ao propósito de uma instituição assistencial dessa época. Para a diretora do asilo 
essa era uma instituição reconhecidamente produzida pelo empenho de agentes externos ao poder público, "prova cabal do esforço dos directores", na qual os cidadãos "poderão ver para o que são empregados os donativos do hospitaleiro povo desta terra" (ASYLO, 1922, p. 6). E qual a razão para se orgulhar disso?

O primeiro motivo era o esforço para levantar o prédio, a sede própria do asilo, "feita unicamente com as esmolas do povo", sendo então "um abrigo seguro e confortável, edificado pelos homens livres e independentes desta terra" (ASYLO, 1922, p. 6). Junto dessa causa de orgulho, havia outro motivo para comemorar pelo fato de esse orfanato ser "uma gloria para Ribeirão Preto que conta em seu seio, além das muitas instituições de ensino, também um Asylo para amparar, educar e instruir creanças orphans e pobres" (ASYLO, 1922, p. 6). Logo, a cidade tinha nas escolas, subvencionadas ou mantidas diretamente pelo Estado e pelo município, a primeira instituição, perante outras, a receber as crianças, ainda que parcelas consideráveis do contingente de escolares não fossem atendidas, conforme sucessivos relatórios de seus prefeitos, entre 1903 e 1929 (FONSECA, 2009), passando, a partir de então, a contar com uma organização especialmente definida para um contingente infantil específico: os órfãos.

Curiosamente, a cidade passou a dispor, desde 1917, dos serviços desse orfanato, cuja inspiração, pelos menos quanto aos princípios e quanto ao público atendido - meninas -, liga o estabelecimento de Ribeirão Preto à obra de Anália Franco, conhecida na capital e em outras partes do Estado. Até o ano de criação do orfanato ribeirão-pretano, outros similares existiam em cidades paulistas, muitos deles batizados com o nome de sua inspiradora, Anália Franco. Para tal homenagem, não contava apenas a condição de figura emérita da caridade, junto da posição de liderança de esforços para a educação feminina. Merece consideração igualmente o fato de Anália Franco ter interlocutores no governo paulista, de ser filiada ao Partido Republicano Paulista (PRP) e de possuir vínculo com espíritas e maçons, estes os inauguradores e mantenedores do asilo de Ribeirão Preto (OLIVEIRA, 2007). Por último, conta a condição de mulher portadora e divulgadora de ideias e produtora de ações, concretizadas nos asilos, creches, escolas e colônias com que contribuiu diretamente ou que inspirou, na fundação.

As escolas, os asilos, as colônias e as creches que Anália Franco ajudou a criar, em geral, concretizaram a prática da assistência institucio- 
nalizada, na capital e no interior de São Paulo. Em Ribeirão Preto, pelo fato de ser precursor, o Asylo de Orphans estabeleceu no município essa forma de atuar. Antes de 1917, na cidade de São Paulo, receber, alimentar, criar, disciplinar, instruir e encaminhar socialmente meninos e meninas órfãos e/ou abandonados, recolhidos das ruas ou entregues pelos pais, compunham o conjunto de ações praticadas por instituições, fossem públicas ou particulares. Em 1917, os criadores do asilo de Ribeirão tinham as realizações de Anália Franco como referência e, tão logo, exemplo para modelar a criação de um estabelecimento na cidade. A diretora, Anita dos Santos, evocava a figura de "D. Anália Franco", na solenidade de abertura do novo prédio, em 1922, lembrando que "si hoje lhe fosse dado o poder de quebrar o somno eterno que a retem nas alturas infinitas, sorriria de prazer em ver que as creanças a quem ella tanto amou, hoje tem um abrigo seguro e confortável, edificado pelos homens livres e independentes desta terra!" (ASYLO, 1922, p. 6).

A cidade contava, até existir o Asylo, com "muitas instituições de ensino", mas ainda necessitava de meios para lidar com a infância abandonada. Essa necessidade não era nova em Ribeirão Preto e nem a constatação de que uma instituição seria a solução possível. Em janeiro de 1913, o editor do Díario da Manhã, Enéias da Silva (1913, p. 1), reclamava "Pela infancia abandonada" alguma solução, propondo "a ideia de congregar os bons elementos desta cidade ou deste município para fundação de um estabelecimento ou de um instituto de protecção à infancia abandonada, ás creanças de um e de outro sexo, atiradas pela miséria ou pelo abandono dos Paes no vórtice da perdição”. E a quem se dirigia o editorialista? Ele responde:

Por vezes tenho externado esse pensamento a varias pessoas de collocação social e directamente interessadas pela missão que na sociedade exercem, e entre estas, posso citar o exc. Sr. Dr. Polycarpo, juiz de direito da comarca e o revimo pe. Euclides Carneiro, recordando até que ao ultimo fiz sentir a necessidade em que se achava a igreja catholica de Ribeirão Preto de impulsionar ou auxiliar fortemente essa iniciativa, dando assim mostras de seu amor aos pequenos (SILVA, 1913, p. 1).

Os nomes citados pelo editorialista, assim lembrados em razão das posições ocupadas, representam certa forma de agir quando se tratava da proposta de estabelecer uma instituição para assistir os necessitados: 
recorrer aos nomes de projeção da localidade, uns posicionados numa confissão religiosa, outros integrados à administração ou a algum poder público, um benemérito ou membro da elite capaz de contribuir em prestígio ou materialmente para o projeto. Essa era a estratégia que costumava associar as expressões da sociedade civil e os representantes do poder público num esforço/causa comum: as crianças pobres.

De forma autóctone, Ribeirão Preto produzia pobres e miseráveis porque recebia imigrantes, dentre os quais certo contingente não era integrado ou deixava os processos produtivos cafeeiros, causa maior de sua vinda, enquanto levas de migrantes circulavam entre Minas Gerais e a região mogiana, sem meios para trabalhar, acumular e sobreviver, chegando até a cidade para "tentar a vida". O noticiário local ${ }^{8}$, inclusive, na crônica da vida diária, informava sobre casos como esse em que o "sr. dr. delegado de policia desta cidade passou attestado de indigencia a favor de Alfredo Maroni, que segue para a Itália” (A CIDADE, 1912a, p. 1). Uma vez miseráveis, tanto os estrangeiros quanto os nacionais podiam tornarse pedintes, devendo receber a autorização da polícia local, como fizeram um imigrante e um nativo, "a fim de mendigar pelas ruas da cidade", recorrendo ao "dr. Delegado regional", que "forneceu chapas de licença a Luiz Dinarelli, italiano, de 60 annos e a José Lima da Silva, brasileiro, de 23 annos" (A CIDADE, 1917a, p. 1).

Em paralelo, o aviltamento dos salários e as oscilações do custo dos alimentos, da moradia e das possibilidades de engajamento no trabalho pressionavam os pobres. Na mesma época das greves de 1917, na capital paulista, o custo de vida deu causa a uma convocação de greve em Ribeirão Preto, transcrita pelo $A$ Cidade (1917b, p. 1):

"Aviso ao operariado".

A exemplo da attitude dos operarios da capital e demais cidades do interior, reclamando dentro do direito e da lei contra a actual carestia de vida, os operairos da Companhia Antarctica, banco Constructor e outros, convidam s operarios em geral desta cidade a se reunirem 5. Feira, 26, ás 7 horas da tarde em frente ao theatro Carlos Gomes, afim de deliberarem, um comício pacífico, a attitude a assumir ante os patrões em beneficio da classe operária.

De forma combinada, devido à referência em modelos externos, e em razão de criações locais, a assistência era praticada na cidade com o fim de responder setorialmente aos efeitos desses processos de empobre- 
cimento de sua população. A resposta à pobreza era setorial porque, para agir sobre essas expressões das questões sociais locais, estavam à disposição de uma parte a repressão e, de outra, a caridade e a assistência para atenuar as necessidades dos pobres e dos miseráveis. Com o fim de conter a insurgência dos trabalhadores nas fazendas e na cidade, a força policial era, a todo tempo, mobilizada, assim como, para reprimir a pequena criminalidade, os pedintes e as demais ameaças à ordem pública, a ponto de ser comum a notícia de "Caça aos vagabundos", a exemplo dessa ocasião, na qual o "major Antonio Alves da Costa Ferreira, subdelegado de policia, deu hontem caça aos vagabundos que infestam alguns pontos da cidade" e "intimou os proprietarios de botequins que não admittam reuniões dessa gente em suas casas" (A CIDADE, 1912b, p. 1). Ao passo que aconteciam essas reprimendas aos desocupados, entre os desvalidos de Ribeirão Preto, seus filhos eram aqueles para quem o editorialista há pouco citado reclamava solução.

Entretanto, a solução proposta estava referenciada num modelo de assistência institucional à infância que ainda não fora concretizado em Ribeirão Preto. Antes de contar com asilos e institutos de proteção, a tutela e os contratos de soldada, por exemplo, eram práticas conhecidas em Ribeirão, desde o século XIX, e respondiam pelos meios de transferir crianças da guarda dos pais para as famílias dos contratantes ou, ainda, como forma de criar os órfãos. Na verdade, a tutela e o contrato de soldada eram institutos jurídicos antigos, originários das Ordenações do Reino, e aplicados largamente no Brasil até o Código Civil de 1916 (LEAL, 1930). Apesar de substituir as ordenações, o código brasileiro continuou a determinar como centro do pátrio poder o pai, uma vez que, em seu lugar, os parentes de sexo masculino seriam as escolhas preferíveis para nomear o tutor de uma criança, à semelhança do que legislavam as Ordenações Filipinas (LEAL, 1930).

Sem pretender simplificar os institutos jurídicos da tutela e da soldada e as relações sociais nas quais eram aplicados, é certo que o fato de crianças órfãs, desvalidas ou não, e filhas de pais e/ou mães pobres serem incluídas numa outra família descreve um tipo de recurso, se não uma estratégia, vigente em Ribeirão Preto e que respondia, parcialmente, pela criação dos filhos sem pais e se servia do trabalho subalterno de meninos e meninas. Durante um período de 55 anos, entre 1874 e 1931, que passa do Império à República, os autos de tutela, curatela e os contra- 
tos de soldada somam 218 processos no Primeiro Ofício da Comarca de Ribeirão Preto?. As situações que levaram a esses processos são variadas, embora existam algumas frequentes, como o conflito de interesses das partes envolvidas no auto, quando se trata das relações entre parentes da criança tutelada e o tutor, da cobrança das obrigações relativas à contratação dos serviços de um menino ou menina, mediante o compromisso de remuneração (o contrato de soldada), e da necessidade de prestação de contas dos curadores dos bens herdados por menores, quando órfãos.

Até que o primeiro asilo para órfãos existisse, em Ribeirão Preto, em 1917, quando se tratava de criar os filhos sem pais, ou apenas sem o pai, a tutela era o recurso aplicável sobre as crianças pobres ou sobre as herdeiras de bens. Além dessa situação, os processos de tutela demonstram que, em Ribeirão Preto, era comum a recolocação de crianças filhas de pais falecidos ou ausentes junto de outros familiares, havendo assim razão para demandar ao judiciário local o reconhecimento do novo ente responsável. Mesmo na época do asilo de órfãos da cidade, o Anália Franco, era frequente o recurso à tutela para reparar situações de abandono e orfandade. O próprio Asilo Anália Franco previa, em seu regulamento, que suas internas ingressariam mediante "interferência do curador geral de orphans, que dará a directoria do asylo, a renuncia paternal de accordo com as leis civis em vigor" (ASYLO, 1922c, p. 1).

$\mathrm{Na}$ tutela, os encaminhamentos das crianças formavam um circuito família-família, isto é, as crianças tuteladas, fossem órfãs pobres ou herdeiras, eram alocadas do seu grupo familiar original para outro, às vezes dos colaterais ou, em outras ocasiões, de pessoas sem parentesco. Quando o "Asylo Anália Franco" recebeu suas primeiras internas, em 1917, outro circuito entrou em atividade em Ribeirão Preto: família-instituição. Se, na aplicação da tutela, em Ribeirão Preto, havia nos processos a influência de interesses quanto à herança, de resíduos de vínculos de parentesco que permitiam a um colateral ser tutor ou, em alguns casos, a motivação era a intenção de usufruir dos serviços de um menino ou menina, como praticado na soldada, no circuito família-instituição, o "Asylo" determinava os critérios de ingresso das internas, se pautava por um programa instrutivo/educativo e previa meios para o encaminhamento das asiladas. Em comparação com a tutela, na qual a criança era absorvida pela vida familiar de outro e nela permanecia por tempo indefinido, na instituição, a lógica operante era a do percurso que iniciava com o recebimen- 
to da asilada, seguia com a sua criação e findava com a previsão do seu desligamento:

$\int 1^{\mathrm{O}}$ - Para admissão de uma criança no Asylo, são requisitos: a) ser orpham e pobre, b) ser menor de dez annos, c) trazer documentos passados pelo curador geral de orphans, tutores ou parentes collateraes, d) attestado medico que garanta o bom estado de saúde e respectivo attestado de vacina, e) apresentar a directoria, documento assignado por tres pessoas de reconhecida idoneidade que affirmem o desprezo dos paes pela criança e neste caso, só pode ser admittida com a interferência do curador geral de orphans, que dará a directoria do asylo, a renuncia paternal de accordo com as leis civis em vigor.

[...] $\int 3^{\mathrm{O}}-\mathrm{A}$ emancipação das orphans, da-se aos vinte annos de idade, salvo motivo de casamento, que será feito com aquiescência da directoria. (ASYLO, 1922c, p. 5101)

Assim, o asilo ribeirão-pretano viabilizou outra forma de assistir crianças sem pais ou abandonadas, dessa vez deslocando o encaminhamento de órfãos e abandonados dos arremedos e simulações de substituição familiar próprios da tutela, para outro ambiente e para outros agentes. Pelo fato de estabelecer lugares exteriores à vida familiar, quando não em substituição, no caso dos órfãos, sob o fim de abrigar, criar e instruir os atendidos, suas realizações se inscrevem no campo da assistência infantojuvenil em ambiente institucional.

Para tanto, a versão ribeirão-pretana modelou seu estatuto, seus processos instrutivos e educativos, bem como suas convicções, em conformidade com as ideias, propostas e realizações de Anália Franco, na cidade e no Estado de São Paulo. A começar pela coincidência de princípios e pelo modelo institucional, há mais convergências do que diferenças entre o asilo de Ribeirão Preto e seus congêneres paulistanos. Desde os primeiros movimentos de fundação da Associação Feminina Beneficente e Instrutiva (AFBI), da qual Anália Franco foi fundadora e ativa liderança, os fins dessa organização eram "não só distribuir o pão que mata a fome, como o pão dos bons exemplos, da educação e do amor de Deus e do amor ao próximo, o que forma boas mães de família, o que faz o cidadão honrado e o operario laborioso, sem contanto filiar-se a credo algum, a fim de abranger todas as classes sociaes" (ASSOCIAÇÃO, 1903, p. 218). Desse modo, a AFBI assumia princípios cristãos e, ao mesmo tempo, não se filiava a determinada confissão religiosa. 
Sob princípios semelhantes, o "Asylo de Orphans Anália Franco de Ribeirão Preto", desde seu regimento, assumia a condição de "instituição humanitária cujo programma é praticar a caridade moral, intelectual e material ás criancinhas orphans sem distinção de cor, nacionalidade e crença religiosa", enfatizando o propósito de oferecer "manutenção, educação e instrução, sem o menor constrangimento de opiniões religiosas, respeitando todas as crenças" (ASYLO, 1922c, p. 5101).

Em comparação com as realizações da AFBI, em São Paulo, a cidade de Ribeirão Preto esperou até 1917 para ter seu primeiro orfanato e, no mesmo ano, outro modelo de instituição iniciava suas atividades: o Instituto de Proteção e Assistência à Infância. Com essa organização local, um campo da ação institucional sobre a infância pobre, comum durante a Primeira República, estava contemplado, uma vez que prestava "serviços de assistencia medica, pharmceutica, alimentar e dentaria", bem como distribuía leite aos "protegidos" (INSTITUTO, 1922, p. 1).

O nome dessa organização ribeirão-pretana imitava o célebre IPAI, do Rio de Janeiro, fundado por Moncorvo Filho, em 1901, assim como havia semelhança quanto ao tipo de ação desenvolvida por ambos e pelo fato de serem liderados por médicos. O IPAI de Ribeirão Preto também era conhecido pelo nome de seu fundador, o médico Antonio Gouveia, e, conforme a conexão formal entre os dois institutos, ratificada pelo Decreto Federal 3.877 de $1919^{10}$, a organização, os propósitos e os apoiadores do IPAI de Ribeirão Preto apresentavam características que remetiam ao modelo do Instituto do Rio de Janeiro. Além de seu fundador, o IPAI ribeirão-pretano contava com um grupo de diretoras originárias das famílias cujos membros estavam integrados ao circuito do poder político e institucional local, formado pelo trinômio Diretório do Partido Republicano Paulista-Câmara Municipal-Prefeitura. A presidente do Instituto, Anita Procópio Junqueira, era casada com o presidente da Câmara Municipal entre 1920 e 1926, Francisco da Cunha Junqueira, mais tarde deputado estadual em São Paulo. Ao lado de Maria Conceição Junqueira Ferraz, Sylvia Stauffer e Benedita Gomide Morgan, além de comporem a diretoria, Anita Junqueira e suas colegas formavam um grupo de apoiadoras com vínculos familiares, políticos e de classe, aos quais recorriam para ativar uma rede de apoios ao IPAI, em Ribeirão Preto, algo comum ao estabelecimento de alianças entre o público e o privado, sob o fim de praticar a assistência à infância. 
Com o IPAI e o Asilo Anália Franco, duas versões da assistência institucional à infância produzidas e praticadas durante a Primeira República, no Brasil e em São Paulo, tinham seus representantes em Ribeirão Preto. Restava ainda um exemplar das instituições disciplinares, largamente difundidas durante essa mesma época.

Sem resultar de alguma ação local, embora Enéias da Silva mencionasse, no editorial antes citado, que a Câmara Municipal adquiriu um terreno, por volta de 1913, "com o fim de doal-o ao Governo do Estado, se este ali estabelecesse um instituto disciplinar" (SILVA, 1913, p. 1), Ribeirão Preto recebeu um estabelecimento desse tipo em 1922. Nesse ano, o Patronato Agrícola "Diogo Feijó" passou a ser o representante, em Ribeirão Preto, dos modelos institucionais vigentes durante a Primeira República, quando se tratava de recolher das ruas, tutelar e instruir meninos, fazendo uso do trabalho.

Diferente do IPAI e do Asilo Anália Franco, o Patronato foi instalado por iniciativa do governo federal, uma vez que pertencia ao Ministério da Agricultura, que adotou esse modelo em vários estados e o manteve até 1930, quando todos foram desativados (OLIVEIRA, 2003). Nas justificativas para a criação dos patronatos, presentes no relatório do Ministério da Agricultura do exercício de 1918, era lembrada a missão do governo de "organizar a assistência publica em favor dos pequeninos enjeitados da sorte e de preparar, com essa materia prima, uma geração nova de trabalhadores familiarizados com a mecânica agrícola, versados na pratica dos manejos e execução dos mistéres que conduzem á obtenção (...) dos produtos agrícolas", razão pela qual era necessário fundar "Patronatos Agrícolas numerosos e espalhados pelo interior de todos os Estados da Republica" (BRASIL, 1918, p. 138). Com esse fim, o "decreto n. 12.893, de 28 de fevereiro de 1918" autorizou o Ministério da Agricultura a "crear instituições dessa natureza nos Postos Zootechnicos, Fazendas-Modelo e estabelecimentos outros, com o duplo objectivo de socorrer a infância desherdada e formar cidadãos uteis á pátria, pelo cultivo da hygiene, da moral, da instruccção e do trabalho ordenado e methodico" (BRASIL, 1918, p. 138139). Por coincidência, Ribeirão Preto possuía, há algum tempo antes de 1922, um Posto Zootécnico e, nesse mesmo ano, o Patronato foi instalado nesse local, onde funcionou até 1926, quando não recebeu mais internos. 
A diferença marcante do Patronato em comparação com o Asilo Anália Franco e o IPAI-RP não era apenas o fato de sua especificidade quanto aos métodos de atuação sobre a infância, a origem deles e suas justificativas legais. Na perspectiva da interiorização, o Patronato é a instituição que mais representa um modelo externo, trazido pronto para ser instalado na cidade. O processo de sua origem, embora um instituto disciplinar fosse pretendido, segundo Enéias da Silva, não indica articulações com filantropos, políticos ou expoentes das ações assistenciais ribeirãopretanas. Ao contrário, a existência do Patronato indicava mais a ação institucional do Ministério da Agricultura, visando a disseminar esse modelo pelo interior paulista e do Brasil.

\section{A interiorização: entre modelos externos e soluções locais}

A tese da interiorização da assistência trata da adoção de modelos produzidos em outras localidades e da comparação com a elaboração local de respostas aos problemas da pobreza e do abandono de crianças. O centro e a ponta desse processo são, respectivamente, São Paulo e Ribeirão Preto, sendo a primeira a cidade onde ideias e práticas foram produzidas e concretizadas em instituições e a segunda, a localidade interiorana, representando aquela que modelou suas instituições conforme essas influências de forma a elaborar respostas próprias para o problema da infância pobre. Portanto, seja pela referência seja pela reprodução de modelos, pois a última década do XIX e as duas primeiras do século XX são o tempo instituinte da assistência particular prestada ao público, da elaboração do arcabouço jurídico sobre a menoridade, da consagração da prática de criação de órfãos e abandonados em instituições fechadas, do ensino de ofícios subalternos e do encaminhamento social para atividades geralmente servis como alternativas à vida dos internos fora do ambiente institucional, é possível caracterizar que, até meados da década de 1930, essas tendências se territorializam junto com pessoas, ideias e instituições, no interior de São Paulo, a exemplo de Ribeirão Preto.

Assim, com o Asilo Anália Franco, o Instituto Antonio Gouveia e o Patronato Agrícola "Diogo Feijó", Ribeirão Preto conheceu, respectivamente, a prática de três ordens de instituições e as formas de ação que praticavam. Com o Asilo Anália Franco, a assistência asilar, a substituição 
da família, a criação e o encaminhamento de órfãos e abandonados contaram com os serviços desse estabelecimento para levar para a cidade e nela estabelecer esses modos de agir consagrados tempos antes em São Paulo, pois, além da necessidade da formação, ministrada na relação diária entre os assistidos e o corpo de funcionários, devido a terem incluído entre seus propósitos a tarefa de instruir, orfanatos, seminários e asilos prolongaram sua intervenção para além de prover, associando o futuro desligamento de seus assistidos ao aprendizado de algum ofício, capaz de dotá-los de meios de subsistência. Assim se organizaram o Seminário da Glória e Colégio D. Carolina Tamandaré, em São Paulo, bem como o "Asylo de Orphans Anália Franco", em Ribeirão Preto, por exemplo, quando definiram certas ocupações como capazes de prover suas ex-internas, ou o casamento e o magistério como dois horizontes possíveis e visados.

Quanto ao Instituto de Proteção, coube a ele e a seus fundadores implantar, em Ribeirão, a ação higienista, modelado pelos similares de outras partes. E, por fim, o Patronato Agrícola, quando instalado em Ribeirão Preto, apesar de ser produzido externamente, viabilizou a interiorização da versão disciplinar e corretiva das instituições para menores, tão conhecidas e adotadas durante a Primeira República. 


\section{Referências}

A CIDADE. Indigente. Ribeirão Preto, n. 2241, p. 1, 11 jan. 1912a.

A CIDADE. Caça aos vagabundos. Ribeirão Preto, n. 2363, p. 1, 15 jun. 1912b.

A CIDADE. Mendicidade. Ribeirão Preto, n. 3903, p. 1, 7 fev. 1917a.

A CIDADE. Rumores de Gréve. Ribeirão Preto, n. 4038, p. 1, 25 jul. $1917 \mathrm{~b}$.

AMARAL, Antonio Barreto do. Dicionário de História de São Paulo. São Paulo: Imprensa Oficial, 2006. (Coleção Paulística, v. 19)

ASSOCIAÇÃO FEMININA BENEFICIENTE E INSTRUCTIVA DO ESTADO DE SÃO PAULO. Estatutos da Associação, Beneficiente e Instructiva do Estado de S. Paulo. Diário Oficial do Estado de São Paulo, São Paulo, p. 218, 27 jan. 1903

ASYLO DE ORPHANS ANALIA FRANCO DE RIBEIRÃO PRETO. Livro de atas. Ribeirão Preto: [s.n.], 1922a. (manuscrito).

ASYLO DE ORPHANS ANALIA FRANCO DE RIBEIRÃO PRETO. Requerimento. Ribeirão Preto: [s.n.], 1922b. [Datilo. Arquivo Público e Histórico de Ribeirão Preto, Requerimentos diversos, 1920-1925.]

ASYLO DE ORPHANS ANALIA FRANCO DE RIBEIRÃO PRETO. Regulamento do Asylo de Orfhans Analia Franco. Diário Oficial do Estado de São Paulo, São Paulo, n. 171, v. 34, p. 1, 2 ago. 1922c.

ASYLO DE ORPHANS ANALIA FRANCO DE RIBEIRÃO PRETO. Livro de atas. Ribeirão Preto: [s.n.], 1923. (manuscrito).

BACELLAR, Carlos de Almeida Prado. O apogeu do café na Alta Mogiana. In: BACELLAR, Carlos de Almeida Prado; BRIOSCHI, Lucila Reis (Org.). Na estrada do Anhanguera: uma visão regional da história paulista. São Paulo: Humanitas/FFLCH/USP, 1999.

BRASIL. Ministério da Agricultura. Relatório apresentado ao Presidente da República dos Estados Unidos do Brasil pelo Ministro da Agricultura, Indústria e Commercio, Dr. João Gonçalves Pereira Lima. [S.l.: s.n.], 1918.

BRUNO, Ernani Silva. Histórias e tradições da cidade de São Paulo: metrópole do Café (18721918), São Paulo de agora (1919-1954). 3 ed. São Paulo: HUCITEC/Prefeitura do Município de São Paulo, 1984. v. 3.

CÂMARA MUNICIPAL DE RIBEIRÃO PRETO. Relatório apresentado pelo prefeito municipal Dr. Manoel Aureliano de Gusmão na sessão de 10 de janeiro de 1903. São Paulo: Duprat \& Comp., 1903.

CÂMARA MUNICIPAL DE RIBEIRÃO PRETO. Relatório apresentado em sessão de 15 de janeiro de 1920, pelo Dr. Joaquim Macedo Bittencourt, Prefeito Municipal. Ribeirão Preto: Typ. da Casa Selles, 1920.

CÂMARA MUNICIPAL DE RIBEIRÃO PRETO. Relatório da Prefeitura, correspondente ao exercício de 1923, apresentado à Câmara Municipal em sessão de 26 de abril de 1924. Ribeirão Preto: Typ. Livro Verde, 1924.

CÂMARA MUNICIPAL DE RIBEIRÃO PRETO. Relatórios correspondentes ao exercício de 1928, apresentados á Câmara Municipal em sessão de 15 de janeiro de 1929, pelo presidente Dr. Joaquim Camillo de Moraes Mattos e pelo prefeito municipal José Martimiano da Silva. Ribeirão Preto: Casa Beschizza, 1929.

CAMPOS, Candido Malta; GAMA, Lucia Helena; SACHETTA, Vladimir. São Paulo: 
metrópole em trânsito: percursos urbanos e culturais. São Paulo: Senac, 2004.

FERREIRA, Tolstoi de Paula. Subsídios para a história da assistência social em São Paulo. Revista do Arquivo Municipal de São Paulo, São Paulo: Departamento de Cultura, v. 67, jun. 1940.

FONSECA, Sérgio César da. A assistência à infância pobre na República Velha: comparações entre São Paulo e Ribeirão Preto (1900-1917). Cadernos de História da Educação. Uberlândia: Universidade Federal de Uberlândia, v. 8, n. 1, p. 203-220, jan.-jun. 2009.

FRANCO, João Evangelista. O serviço de assistência aos menores no Estado de São Paulo. Revista do Arquivo Municipal. São Paulo, v. 97, ano 10, p. 7-44, set.-out 1944.

INSTITUTO DE PROTEÇÃO E ASSISTÊNCIA À INFÂNCIA DE RIBEIRÃO PRETO. Requerimento. Ribeirão Preto: [s.n.], 1922. (datilo)

KFOURI, Nadir Gouvêa. Estabelecimentos particulares cujo objetivo é prestar assistencia aos menores abandonados do Município de São Paulo. São Paulo: [s.n.], [1936]. (datilo).

LAURIANO, Monsenhor Dr. João. Subsídios para a história religiosa de Ribeirão Preto (18451905). Ribeirão Preto: Cúria Metropolitana de Ribeirão Preto, 1973.

LEAL, Antonio Luiz da Câmara. Manual Elementar de Direito Civil. São Paulo: Saraiva \& Cia Editores, 1930.

LOWRIE, Samuel H. Assistência filantrópica na cidade de São Paulo. Revista do Arquivo Municipal. v. 27, ano 3, São Paulo: Departamento de Cultura, Set. 1936.

MARCÍLIO, Maria Luíza. História social da criança abandonada. São Paulo: Hucitec, 1998. MEMÓRIA urbana. A grande São Paulo até 1940. São Paulo: Arquivo do Estado; Imprensa Oficial, 2001. v. 2.

MENSAGEM apresentada ao Congresso Legislativo, em 14 de julho de 1927, pelo Dr. Antonio Dino da Costa Bueno, Presidente do Estado de São Paulo. In: SÃO PAULO. Relatórios dos Presidentes de Estado: $1^{\text {a }}$ República, 1890-1927 (microfilme). Rio de Janeiro: Biblioteca Nacional, 1984. 542 fotogramas, $35 \mathrm{~mm}$.

MOACYR, Primitivo. A instrução pública no Estado de São Paulo: primeira década republicana (1890-1893). São Paulo: Cia. Editora Nacional, 1942.

MONBEIG, Pierre. Pioneiros e fazendeiros de São Paulo. São Paulo: HUCITEC/Polis, 1984.

MOTTA, Cândido N. N. da. Os menores delinqüentes e o seu tratamento no Estado de São Paulo. São Paulo: Tipografia do Diário Oficial, 1909.

OLIVEIRA, Eliane de Christo. Anália Franco e a Associação Feminina Beneficente e Instrutiva: idéias e práticas educativas para a criança e a mulher (1870-1920). [2007]. Dissertação (Mestrado) - Universidade São Francisco, 2007.

PETRONE, Pasquale. No cinturão em torno do centro da cidade, definiram-se inúmeras pequenas Itálias. In: MEMÓRIA urbana. A grande São Paulo até 1940. São Paulo: Arquivo do Estado; Imprensa Oficial, 2001.

PRATES, Prisco da Cruz. Ribeirão Preto de outrora. Ribeirão Preto: [s.n.], 1956.

REIS, Nestor Goulart. São Paulo: vila, cidade, metrópole. Prefeitura Municipal de São Paulo: 2004.

SÃO PAULO. Decreto Estadual n. 91, 18 ago, 1892. Approva os estatutos apresentados pelo dr. Manoel Baptista da Cruz Tamandaré, para o collegio-Dona Carolina Tamandaré. Diário Official do Estado de São Paulo, São Paulo, n. 374, ano 2, p. 1, 20 ago. 1892.

SILVA, Enéias da. Pela infância abandonada. Diário da Manhã, Ribeirão Preto, n. 4079, p. 1, coluna 5, 12 jan. 1913. 
TUON, Liamar. O cotidiano cultural em Ribeirão Preto (1880-1920). [1997]. Dissertação (Mestrado em História) - Faculdade de História, Direito e Serviço Social, Universidade Estadual de São Paulo, Franca, 1997.

VASCONCELlOS, Maria da Penha Cunha. (Coord.). Memórias da saúde pública: a fotografia como testemunha. São Paulo: Hucitec/Abrasco, 1995. 


\section{Notas}

1 Duas referências sustentam essa periodização, sendo uma delas o início das atividades, em 1825, dos Seminários de Santana e da Glória, os primeiros estabelecimentos públicos para órfãos na cidade de São Paulo, e a outra é o mapeamento das instituições assistenciais filantrópicas ativas na capital paulista realizado por Samuel H. Lowrie (1936) durante 1935. Sustenta, ainda, essa delimitação o levantamento produzido por Nadir Gouvêa Kfouri, em 1935, sobre estabelecimentos assistenciais para crianças em São Paulo, no qual aparecem informadas como ativas várias instituições citadas no Quadro 1, principalmente aquelas criadas no período de 1892 a 1897.

2 A maior parte dos relatórios conjuntos da Câmara Municipal e da Prefeitura procura justificar que, em razão do montante de impostos arrecadados, as possibilidades de aplicação dos recursos públicos costumavam priorizar os melhoramentos na captação e na distribuição de água, na rede de esgoto, no calçamento das ruas, na limpeza pública, junto do que se nomeava, à época, de "polícia sanitária", nesse caso, uma prática levada a efeito pela Comissão Sanitária local, dotada de poder de polícia para fiscalizar residências e estabelecimentos comerciais (CÂMARA MUNICIPAL, 1920; 1924). Esses eram os compromissos em que as administrações locais se empenhavam, o que abria margem à ação privada, principalmente, quando se tratava de suprir as necessidades impostas pela pobreza. Desse modo, a ação assistencial privada e seus promotores precisavam negociar benefícios, incentivos e subvenções com os ocupantes do poder público.

3 Trata-se do período em que José Alves de Cerqueira César assumiu a presidência do Estado, de 15/12/1891 a 23/8/1892.

4 Em 1890, durante o tempo em que Prudente de Morais foi governador do Estado, o orçamento para o exercício seguinte foi fixado pelo Decreto n. 50, de 28 de abril de 1890, no qual se previam subvenções aos referidos liceus, bem como ao Seminário de Educandas da Glória.

5 As ordens religiosas estavam presentes na cidade de São Paulo desde o século XVI, pelo menos, praticando, entre outros feitos, a caridade aos doentes, aos pobres e a toda sorte de necessitados, embora tal ação ainda não representasse, como ocorreu no século XIX, algo semelhante ao sistema privado de assistência aos desvalidos, conforme indicado por Marcílio (1998).

6 Num artigo também comparativo, discuto (FONSECA, 2009) as relações entre o público e o privado na assistência à infância pobre e abandonada, cotejando, para tanto, as cidades de São Paulo e Ribeirão Preto, durante a Primeira República.

7 Os anuários estatísticos estaduais desse período indicam essa progressão acelerada do crescimento da população da cidade de São Paulo em razão dos números da imigração (MEMÓRIA, 2001). Quando o período é ampliado, no espaço de tempo entre 1890 e 1938, segundo os dados compilados no volume 2 de Memória urbana (2001), os números do crescimento populacional da capital paulista impressionam mais, uma vez que, em 1938, sua população passou da marca de um milhão de habitantes. 
8 Os textos do jornal $A$ Cidade citados neste artigo são provenientes de pesquisa realizada na Biblioteca Padre Euclides, de Ribeirão Preto, e outra parte resulta das transcrições disponíveis no Arquivo Público e Histórico da cidade, doadas pela pesquisadora Liamar Tuon (1997), autora de estudo sobre a cidade na Primeira República.

9 Esses números resultam das pesquisas que realizo no acervo dos processos da Comarca de Ribeirão Preto guardados no Arquivo Público e Histórico da cidade.

10 O Decreto Federal 3.877 de 12 de novembro de 1919 estabeleceu, em seu artigo primeiro, que: "São considerados de utilidade pública a Liga Brasileira contra o Analphabetismo, a Liga Pro-Saneamento do Brasil e o Instituto de Protecção e Assistência á Infância, todos com sede nesta Capital, bem como suas filiaes já existentes”. Para o IPAI de Ribeirão Preto, esse era o decreto com o qual sustentava sua condição de utilidade pública, uma vez que o citava em seus documentos, assumindo, desse modo, um vínculo formal/legal com o IPAI do Rio de Janeiro (INSTITUTO, 1922).

Recebido: 30/09/2010 